
\title{
Reseacch S Suare \\ The Health Scare of COVID-19: Implication of Pandemics and the immune-related pharmaceutical products spillovers in USA
}

Andrew Adewale Alola ( $\sim$ aadewale@gelisim.edu.tr)

Istanbul Gelisim University https://orcid.org/0000-0001-5355-3707

Funmilayo Boluwatife Olowu

Yeditepe University

\section{Research Article}

Keywords: nCOVID-19, pandemic, vitamins, uncertainty, United States

Posted Date: August 19th, 2020

DOI: https://doi.org/10.21203/rs.3.rs-61999/v1

License: (c) (i) This work is licensed under a Creative Commons Attribution 4.0 International License.

Read Full License 


\title{
The Health Scare of COVID-19: Implication of Pandemics and the immune- related pharmaceutical products spillovers in USA
}

\author{
Andrew Adewale ALOLA ${ }^{1,2, *}$ \\ ${ }^{1}$ Department of Economics and Finance \\ Istanbul Gelisim University, Istanbul, Turkey \\ ${ }^{2}$ Department of Financial Technologies, \\ South Ural State University, Chelyabinsk, Russia \\ *Email: aadewale@gelisim.edu.tr
}

\author{
Funmilayo Boluwatife OLOWU \\ ${ }^{3}$ Department of Pharmacy, \\ Yeditepe University \\ E-mail: olowufunmilayo88@gmail.com.
}

Funding: This research did not receive any specific grant from funding agencies in the public, commercial, or not-for-profit sectors.

\section{Declarations of interest: none}




\section{Abstract}

32 In view of the sector-wide effect of the nCOVID-19 pandemic in the United States and the probable 33 effect on certain over-the-counter (OTC) pharmaceutical products, the current study examined 34 potential inflation in the pharmaceutical industry due to uncertainty in pandemics. In this case, the 35 United States' producer price indexes vis-à-vis inflation of the immune-related pharmaceutical 36 items: multivitamin, vitamins nutrients and hematinic (V-N-H), other vitamins (other-V), 37 antidepressant, and antidiabetic were examined alongside the uncertainties arising from the world 38 pandemic and economic policy. Thus, the Diebold and Yilmaz (2012) result implied that the world 39 pandemic uncertainty contributed a significantly huge shock to the entire elements such that the 40 shocks to $\mathrm{V}-\mathrm{N}-\mathrm{H}$ and multivitamins are larger than the other examined pharmaceutical compounds. 41 Importantly, the statistical evidence implied that uncertainty arising from pandemic is responsible

42 for the severity of shock received by the indicated pharmaceutical products as against economic 43 policy uncertainty. Thus, a relevant policy inference is posited from the result of the study.

44 Keyword: nCOVID-19; pandemic; vitamins; uncertainty; United States 


\section{Introduction}

55 After more than 100 years that the influenza pandemic commonly called 'Spanish Flu' of 1918 ravaged the world, the novel severe acute respiratory syndrome coronavirus 2 (known as nCOVID-

5719 or SARS-CoV-2) that has affected more than 216 countries and territories has remained a 58 prevailing mystery. Currently, about 600,000 human lives has been lost and almost 14 million 59 confirmed cases has been recorded globally (World Health Organization, WHO, 2020). Since the 60 emergency of the nCOVID-19 pandemic, governments across the globe and the collaborating 61 effort of both the intergovernmental agencies and the private institutions have extensively 62 deployed various measures to mitigate the spread of the virus or 'flatten the curve'. In addition to 63 some of the measures that have been implemented (such as 'lockdown', 'social distancing, travel 64 restriction/suspension across borders and other measures), scientists have proposed a few 65 inference. So far, the proffered pathogenesis of nCOVID-19 has obviously presented in three 66 phases: (1) the asymptomatic (2) symptomatic but a not severe phase, and (3) the symptomatic 67 stage with a severe and high viral load (Shi et al., 2020). As such, among other factors, the 68 pandemic is expected to have impacted both the manufacturing and the over-the-counter (OTC) 69 pharmaceutical products demand through the application of prevention mechanisms (Singh \& Avikal, 2020; Srivastava \& Wagh, 2020).

71 Accordingly, the nCOVID-19 has been associated with the human immune system (Li et al., 2020;

72 Russell et al., 2020; Shi et al., 2020). In specific, Li et al (2020) opined that the body's humoral 73 and cellular is stimulated by the immunity Antigens in the human cells, thus expectedly preventing 74 the advancement of the nCOVID-19 disease to the severe stage. Indicatively, the appropriateness 75 of human genetic structure, depicting a good health status, is responsible for the response of the 76 endogenous protective immune that is potentially capable of inhibiting the nCOVID-19 viral 
77 replication as an antiviral immunity (Shi et al., 2020). This is because ongoing studies have noted 78 cases of nCOVID-19 sufferers that are either impervious to nCOVID-19 or immunocompromised 79 (Centers for Disease Control and Prevention, CDC, 2020; Nature, 2020). As such, scientists and 80 medical experts have consistently outlined the role of individuals in maintaining a boosted immune 81 system (Brand South Africa, 2020; DW, 2020; Tufan, GÜLER \& Matucci-Cerinic, 2020). In this 82 perspective, in addition to living a healthy lifestyle, and the 'phobia' for COVID-19, the use of 83 supplements and nutritional medications or compounds such as vitamin C, antioxidants and other 84 compounds are being encouraged to booting the human immune system (Amin, 2020; Brand South 85 Africa, 2020).

In view of the above motivation, the current study look at the performance of the pharmaceutical

87 industries, especially those associated with the production of vitamins and other immune-related drugs in the framework of the United States' COVID-19 situation. Although Nicola et al (2020) and Mason-D'Croz et al (2020) have earlier suggested the likelihood of spillover effect of the COVID-19 pandemic to the socio-economic aspects, there is no study that specifically noted a

91 pharmaceutical sector-specific effect from the nCOVID-19 pandemic. Hence, the novelty of the 92 current study is that it offers a highlight of a few important contribution to the existing nCOVID-

9319 literature in a unique pattern. Foremost, the study offers explanation on the probable 94 vulnerability of the producer price index (PPI) vis-à-vis inflation associated with the production 95 of the immune-related pharmaceutical compound or supplements: Vitamins nutrients, hematinic, 96 multivitamin. In context, the United States has reported an overall relative rise in import and export 97 prices since May 2020. In addition, the uncertainty associated with the economic policy and the 98 pandemic (i.e. the economic policy uncertainty and pandemic uncertainty) are employed in 99 examining the vulnerability of the aforementioned pharmaceutical compounds. Thus, with the 
100 aforementioned novel approach and considering that United States has reported more cases and 101 number of death from COVID-19 than any other country in the world $(\sim 3.7$ million reported cases 102 and $~ 140,000$ deaths) according to the Johns Hopkins University and Medicine (2020), this study 103 is capable of providing a new significant insight.

104 In the other section of this study, the material employed, theoretical concept, the discussion of the 105 results, and the conclusion of the study are all described sequentially in section two. The discussion 106 of the results and conclusion remarks are rendered in section three and section four respectively.

\section{2. Material and Theoretical concept}

\subsection{Material}

109 The theoretical concept of the study is based on the use of the producer price indexes of 110 pharmaceutical items: multivitamin, vitamins nutrients and hematinic (V-N-H), other vitamins 111 (other-V), antidepressant, and antidiabetic. The indexes of the aforementioned pharmaceutical 112 materials were retrieved from the Federal Reserve Economic Data, FRED $(2020)^{1}$. In addition, the 113 employed world pandemic uncertainty index (denoted as WPU) and economic policy uncertainty 114 index (denoted as EPU) were retrieved from the world pandemic index (2020) and FRED (2020) 115 respectively. The aforementioned dataset covers the period of June 2001 to February 2020.

\section{$116 \quad 2.2$ Theoretical Concept}

117 In Table 1, the descriptive statistics of the employed aforementioned materials are presented. With 118223 observations, the volatility is observed to be highest in index of antidiabetic, and followed by

\footnotetext{
${ }^{1}$ The Federal Reserve Economic Data, FRED (2020) is available on https://fred.stlouisfed.org/.
} 
119 antidepressant, EPU, other vitamins, V-N-H, WPU, and lastly by multivitamins. Therefore, we 120 proceed to employ the Diebold Yilmaz spillover index approach (Diebold \& Yilmaz, 2012).

121 
122 Table 1: Statistical Inference

123 Common Statistics

\begin{tabular}{lccccccc} 
& WPU & V-N-H & OTHER-V & MULTIVATMINS & EPU & ANTIDIABETIC ANTIDEPRESSANT \\
Mean & 4.782463 & 116.2614 & 123.1605 & 170.9700 & 104.7842 & 733.7027 & 714.6274 \\
Median & 1.882653 & 117.4000 & 127.9000 & 172.1000 & 90.93871 & 570.5000 & 670.2000 \\
Maximum & 141.5323 & 137.8000 & 151.3000 & 184.4000 & 253.9187 & 1506.400 & 1153.100 \\
Minimum & -18.83425 & 98.60000 & 97.80000 & 155.3000 & 38.20903 & 312.5000 & 264.8000 \\
Std. Dev. & 11.84658 & 13.37791 & 19.01948 & 9.681883 & 47.09574 & 392.0075 & 308.3119 \\
Skewness & 8.133492 & 0.246458 & 0.010960 & -0.124159 & 1.136607 & 0.719962 & 0.048979 \\
Kurtosis & 87.24622 & 1.607648 & 1.437808 & 1.591436 & 3.727792 & 1.987633 & 1.426031 \\
Jarque-Bera & 68405.62 & 20.27080 & 22.68026 & 19.00809 & 52.93633 & 28.78807 & 23.10812 \\
Probability & $(0.00000)$ & $(0.00004)$ & $(0.00001)$ & $(0.00008)$ & $(0.00000)$ & $(0.000001)$ & $(0.00001)$ \\
Observations & 223 & 223 & 223 & 223 & 223 & 223 & \\
& & & & & & & \\
\hline
\end{tabular}

125 Note: 


\subsubsection{Spillover effect approach}

128 In this part, the Diebold and Yilmaz (2012) approach is employed to illustrate the Total,

129 Directional, Net, and Net Pairwise Spillovers as the categories of spillover effects. This approach

130 is employed through the covariance stationary VAR (p) of each variable $y$ that can be represented

131 as

132

$$
y_{t}=\sum_{i=1}^{p} \Phi_{i} y_{t-1}+\varepsilon_{t} \square(0, \Sigma)
$$

133 such that

$134 y_{t}=\sum_{i=0}^{\infty} A_{i} \varepsilon_{t-1}$

135 is the moving average of the covariance stationary process and $\mathrm{yt}=\left(\mathrm{y}_{1}, \mathrm{y}_{2 t}, \ldots, \mathrm{y}_{\mathrm{Nt}}\right)^{\prime}$ is $\mathrm{N} \mathrm{x} 1$ vector 136 of the individual return and volatility series. Also, $\Phi$ is $N \times N, \varepsilon$ is the vector of disturbance that 137 are assumed to be independent (not necessarily identically) distributed over time such that $\mathrm{A}_{\mathrm{i}}=\Phi_{1}$ $138 \mathrm{~A}_{\mathrm{i}-1}+\Phi_{2} \mathrm{~A}_{\mathrm{i}-2}+\ldots+\Phi_{\mathrm{p}} \mathrm{A}_{\mathrm{i}-\mathrm{p}}$. $\mathrm{A}_{0}$ is the identity matrix with $N \mathrm{x} N$ dimension, and $\mathrm{A}_{\mathrm{i}}=0$ for all $i<$ 1390.

140 In determining the magnitude of the spillovers among the pharmaceutical items, WPU and EPU, 141 we adopt the conventional VAR framework such that the H-step-ahead forecast error variance 142 contribution becomes

$$
\theta_{i j}^{g}(H)=\frac{\sigma_{j j}^{-1} \sum_{h=0}^{H-1}\left(e_{i}^{\prime} A_{h} \sum e_{j}\right)^{2}}{\sum_{h=0}^{H-1}\left(e_{i} A_{h} \sum A_{h} e_{i}^{\prime}\right)^{2}}
$$


144 Such that the variance matrix of the error vector is $\Sigma, \sigma_{j j}$ is the standard deviation of the error term

145 for variable $j, e_{i}$ is the selection vector with $l=i$ th element and $O=$ otherwise. Then, the diagonally

146 centralized elements (the own variance shares of shocks to variable $y_{i}$ ) is the fraction of the $\mathrm{H}$ -

147 step-ahead error variance in forecasting $y_{i}$, given that $i=1,2, \ldots N$. Also, the off-diagonal (cross

148 variance shares or spillovers) are the fractions of the H-step-ahead error variances in forecasting

$149 y \mathrm{i}$ that are due to shocks to $y_{j}$, given that $j=1,2, \ldots N$ and $i$ is not equal $j$. Furthermore, to use the

150 full information, each entry of the variance decomposition matrix is normalized by taking the row

151 sum such that

152

$\theta_{i j}^{g}(H)=\frac{\theta_{i j}^{g}(H)}{\sum_{j=1}^{N} \theta_{i j}^{g}(H)}$

153 where $\sum_{j=1}^{N} \theta_{i j}^{g}(\mathrm{H})$ (sum of the contributions to the variance of the forecast error) is not equal to

$154 \quad 1$, but $\sum_{j=1}^{N} \tilde{\theta}_{i j}^{g}(H)=1$ and $\sum_{i, j=1}^{N} \tilde{\theta}_{i j}^{g}(H)=N$

155 Consequently, the Total spillover index among the examined commodity markets is provided as

$$
S^{g}(H)=\frac{\sum_{\substack{i, j=1 \\ i \neq j}}^{N} \tilde{\theta}_{i j}^{g}(H)}{\sum_{i, j=1}^{N} \tilde{\theta}_{i j}^{g}(H)} \times 100=\frac{\sum_{\substack{i, j=1 \\ i \neq j}}^{N} \tilde{\theta}_{i j}{ }^{g}(H)}{N} \times 100
$$

157 But, the Total directional spillover exhibits two indicators: "To others" and "From other". Then, 158 the directional spillover index from others is computed as 


$$
S_{i}^{g}(H)=\frac{\sum_{\substack{J=1 \\ j \neq 1}}^{N} \tilde{\theta}_{i j}{ }^{g}(H)}{\sum_{i, J=1}^{N} \tilde{\theta}_{i j}{ }^{g}(H)} \times 100=\frac{\sum_{\substack{J=1 \\ j \neq 1}}^{N} \tilde{\theta}_{i j}{ }^{g}(H)}{N} \times 100
$$

While the directional spillover index to others is calculated as

$$
S_{i}^{g}(H)=\frac{\sum_{\substack{J=1 \\ j \neq 1}}^{N} \tilde{\theta}_{j i}{ }^{g}(H)}{\sum_{i, J=1}^{N} \tilde{\theta}_{j i}{ }^{g}(H)} \times 100=\frac{\sum_{\substack{J=1 \\ j \neq 1}}^{N} \tilde{\theta}_{j i}{ }^{g}(H)}{N} \times 100
$$

162 Moreover, the difference between the 'to other' and 'from others' indicators is calculated using

$$
S_{i}^{g}(H)=S_{. i}^{g}(H)-S_{i .}^{g}(H)
$$

$$
S_{i j}^{g}(H)=\left\{\frac{\tilde{\theta}_{j i}^{g}(H)}{\sum_{i, \mathrm{k}=1}^{N} \tilde{\theta}_{i k}^{g}(H)}-\frac{\tilde{\theta}_{i j}^{g}(H)}{\sum_{\mathrm{j}, \mathrm{k}=1}^{N} \tilde{\theta}_{j k}^{g}(H)}\right\} \times 100=\left\{\frac{\tilde{\theta}_{j i}^{g}(H)-\tilde{\theta}_{i j}^{g}(H)}{N}\right\} \times 100
$$

166 Thus, the current study measures the total spillover index, the contributions of spillovers of the 167 WPU, EMU, and the inflation (producer price indexes) of pharmaceutical items: multivitamin, 168 vitamins nutrients and hematinic (V-N-H), other vitamins (other-V), antidepressant, and 169 antidiabetic. As revealed, the indicated spillover indices and other results are presented in Table 2 170 while respective rolling windows are illustrated in Figure 1. 
Table 2: Spillover indexes for cases of Economic Policy and World Pandemic Uncertainties

\section{With Economic Policy (Panel A)}

\begin{tabular}{|c|c|c|c|c|c|c|c|}
\hline & EPU & $\mathrm{V}-\mathrm{N}-\mathrm{H}$ & OTHER-V & MULTIVATMINS & ANTIDIABETIC & ANTIDEPRESSANT & From Others \\
\hline EPU & 90.9 & 3.5 & 0.9 & 0.1 & 1.4 & 3.1 & 9.1 \\
\hline V-N-H & 0.2 & 81.0 & 7.4 & 2.8 & 7.6 & 0.9 & 19.0 \\
\hline OTHER-V & 0.4 & 29.3 & 54.1 & 13.4 & 1.9 & 0.9 & 45.9 \\
\hline MULTIVATMINS & 2.7 & 14.3 & 1.6 & 79.7 & 0.2 & 1.4 & 20.3 \\
\hline ANTIDIABETIC & 0.1 & 0.2 & 0.4 & 0.4 & 95.5 & 3.4 & 4.5 \\
\hline ANTIDEPRESSANT & 6.7 & 0.5 & 0.1 & 5.2 & 1.6 & 85.9 & 14.1 \\
\hline Contribution to others & 10.1 & 47.8 & 10.5 & 21.9 & 12.8 & 9.8 & 113.0 \\
\hline Contribution including own & 101.1 & 128.8 & 64.5 & 101.6 & 108.3 & 95.6 & $(18.8 \%)$ \\
\hline
\end{tabular}

\section{With Pandemic (Panel B)}

\begin{tabular}{|c|c|c|c|c|c|c|c|}
\hline & WPU & $\mathrm{V}-\mathrm{N}-\mathrm{H}$ & OTHER-V & MULTIVATMINS & ANTIDIABETIC & ANTIDEPRESSANT & From Others \\
\hline$\overline{\mathrm{WPU}}$ & 98.4 & 0.6 & 0.3 & 0.1 & 0.4 & 0.2 & 1.6 \\
\hline $\mathrm{V}-\mathrm{N}-\mathrm{H}$ & 16.3 & 69.4 & 5.5 & 1.9 & 6.1 & 0.8 & 30.6 \\
\hline OTHER-V & 24.4 & 23.6 & 40.3 & 9.3 & 1.6 & 0.8 & 59.7 \\
\hline MULTIVATMINS & 2.1 & 13.5 & 1.4 & 81.3 & 0.2 & 1.6 & 18.7 \\
\hline ANTIDIABETIC & 58.2 & 0.2 & 0.6 & 0.1 & 39.9 & 0.9 & 60.1 \\
\hline ANTIDEPRESSANT & 14.5 & 0.3 & 0.2 & 5.6 & 1.7 & 77.6 & 22.4 \\
\hline Contribution to others & 115.5 & 38.3 & 8.0 & 17.0 & 10.0 & 4.3 & 193.1 \\
\hline Contribution including own & 213.9 & 107.7 & 48.3 & 98.3 & 50.0 & 81.9 & $(32.2 \%$ \\
\hline
\end{tabular}

With both Pandemic and Economic Policy Uncertainties (Panel C)

\begin{tabular}{|c|c|c|c|c|c|c|c|c|}
\hline & WPU & V-N-H & OTHER-V & MULTIVATMINS & EPU & ANTIDIABETIC & ANTIDEPRESSANT & $\begin{array}{l}\text { From } \\
\text { Others }\end{array}$ \\
\hline$\overline{\mathrm{WPU}}$ & 98.3 & 0.6 & 0.4 & 0.1 & 0.0 & 0.4 & 0.2 & 1.7 \\
\hline V-N-H & 20.0 & 66.6 & 5.1 & 1.8 & 0.1 & 5.7 & 0.8 & 33.4 \\
\hline OTHER-V & 23.9 & 23.8 & 40.1 & 9.4 & 0.5 & 1.5 & 0.8 & 59.9 \\
\hline MULTIVATMINS & 1.0 & 13.4 & 1.8 & 81.6 & 0.6 & 0.2 & 1.4 & 18.4 \\
\hline EPU & 91.1 & 1.3 & 0.1 & 0.2 & 6.9 & 0.4 & 0.1 & 93.1 \\
\hline ANTIDIABETIC & 57.0 & 0.2 & 0.6 & 0.1 & 0.2 & 40.9 & 0.9 & 59.1 \\
\hline ANTIDEPRESSANT & 8.3 & 0.5 & 0.0 & 5.5 & 3.6 & 1.5 & 80.6 & 19.4 \\
\hline Contribution to others & 201.2 & 39.8 & 8.1 & 17.1 & 5.0 & 9.6 & 4.2 & 285.0 \\
\hline Contribution including own & 299.5 & 106.4 & 48.2 & 98.7 & 11.8 & 50.6 & 84.8 & $40.7 \%$ \\
\hline
\end{tabular}




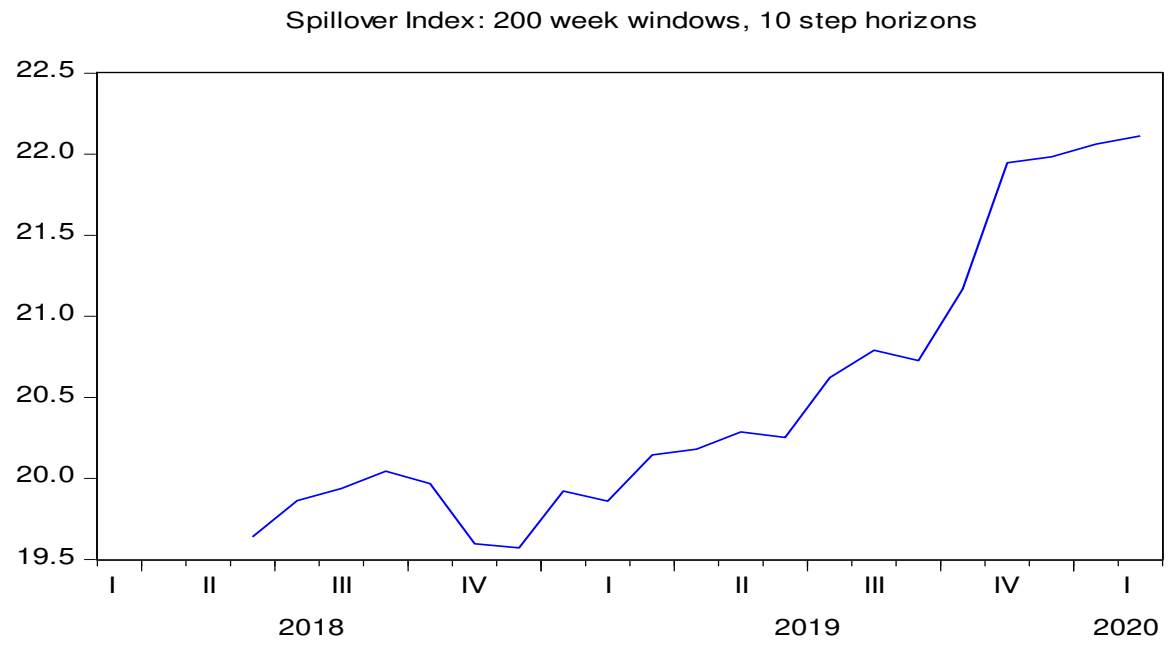

176

A: Rolling window with Economic Policy Uncertainty

Spillover Index: 200 week windows, 10 step horizons

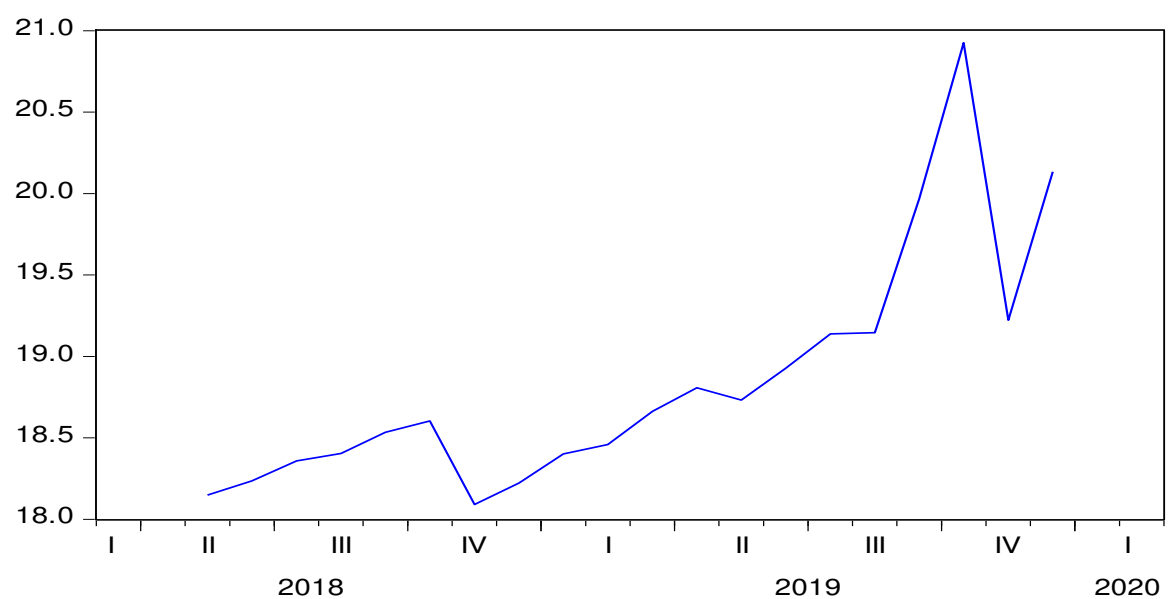

B: Rolling window with the World Pandemic Uncertainty

Spillover Index: 200 week windows, 10 step horizons

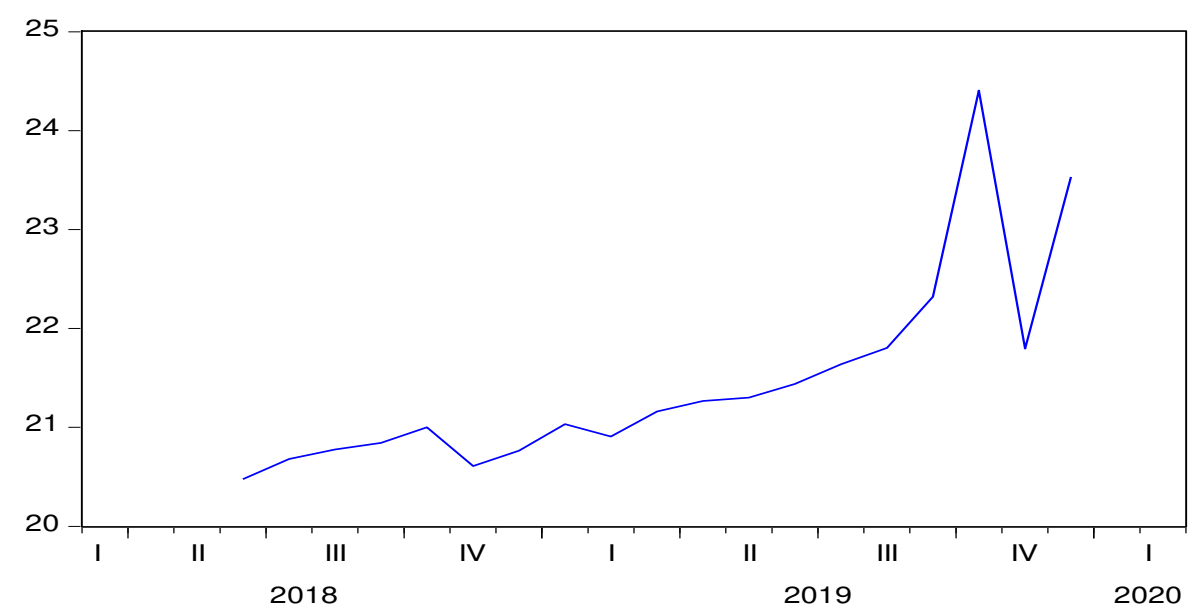

C: Rolling window with Pandemic and Economic Policy Uncertainties

Figure 1: A, B and C are respective visual evidence of 


\section{Findings and discussion}

By employing the step-step procedures (equation 1 to 9) above, the approach is employed for three different categories: (1) using the EPU (result in panel A of Table 2), (2) using the pandemic uncertainty index (result in panel B of Table 2), and (3) employing with both the EPU and WPU (result in panel $\mathrm{C}$ of Table 2). In the panel A, where the EPU was employed with the PPI of the pharmaceutical materials, the total spillover index that signifies the total transfer of information among the variable is $113.0 \%$. However, with the inclusion of the EPU, the total spillover index increased to $193.1 \%$ (see panel B). This implies that the uncertainty caused by the world pandemic is capable of causing the spread of higher level of uncertainty as compared with the uncertainty caused by economic policy (EPU).

In specific, as seen in panel B of Table 2, the world pandemic uncertainty contributes $115.5 \%$ shock to other element of the estimation. In this context, antidepressant receives the highest shock, followed by vitamins nutrients and hematinic (V-N-H) with $38.3 \%$ and multivitamins (5.6\%). In addition, these elements also received the three largest shock from others. Furthermore, the result of the panel $\mathrm{C}$ (Table 2) provides an additional supporting evidence. This result implies that when both EPU and WPU are employed along with the pharmaceutical compounds, the contribution of shock from the WPU to other elements now increased to $201.2 \%$. In this case, vitamins nutrients and hematinic (V-N-H) and multivitamins receives the highest shocks with respective values of $39.8 \%$ and $17.1 \%$. More importantly, the total spillover index (transfer of shock among the estimated elements) now increased to $285.0 \%$. This is an indication that world pandemic uncertainty such as the COVID-19 is capable of contributing a significant amount of shock to the production of pandemic-related medications. 


\section{4. Concluding Remark}

205 This study examined the potential and magnitude of shock associated with production of immune206 related pharmaceutical products or compounds especially in the context of COVID-19 pandemic.

207 Considering that the severity of COVID-19 has been largely linked with the sufferers' immune 208 system and evidence of underlying illness, the industrial production of immune-related 209 pharmaceutical drugs such as the multivitamin, vitamins nutrients and hematinic (V-N-H), 210 antidepressant, and antidiabetic is expected to increase during the pandemic. As such, the current 211 study examined the spillover effect arising from the world pandemic uncertainty and economic 212 policy uncertainty to the producer price indexes of pharmaceutical items: multivitamin, vitamins 213 nutrients and hematinic (V-N-H), other vitamins (other-V), antidepressant, and antidiabetic in the 214 United States. The result posited that the uncertainty arising from the world pandemics such as the 215 COVID-19 in the United States is responsible for high shock in the producer price index of all the 216 examined pharmaceutical items. The study further showed that the shock arising from the world 217 pandemic uncertainty is significantly higher than that of the economic policy in the United States.

218 By implication, if the United States is interested in curbing the adverse effect of inflation associated 219 with the immune-specific pharmaceutical compounds, the government should foster policy that 220 target the COVID-19 scenario in the United States. With such effective policy, potential surge in 221 inflation in the pharmaceutical industry can be curbed, thus reducing the burden the consumers. 


\section{Reference}

227 Amin, S. (2020). The psychology of coronavirus fear: Are healthcare professionals suffering from corona-phobia?. International Journal of Healthcare Management, 1-8.

229 Brand South Africa (2020). The importance of your immune system in fighting COVID-19 and 230 how to keep it healthy. https://www.brandsouthafrica.com/covid19/the-importance-ofyour-immune-system-in-fighting-covid-19-and-how-to-keep-ithealthy?gclid=EAIaIQobChMI59j8jvaB6gIVdoBQBh0xLQHJEAAYASAAEgLv4fD_B wE. (Accessed 18 July 2020).

Diebold, F. X., \& Yilmaz, K. (2012). Better to give than to receive: Predictive directional measurement of volatility spillovers. International Journal of Forecasting, 28(1), 57-66.

236 DW (2020). COVID-19: How to boost the immune system with vitamins. https://www.dw.com/en/coronavirus-and-how-to-boost-the-immune-system-withvitamins/a-53360766. (Accessed 18 July 2020).

239 The Federal Reserve Economic Data, FRED (2020). https://fred.stlouisfed.org/.(Accessed 18 July 2020).

241 Li, X., Geng, M., Peng, Y., Meng, L., \& Lu, S. (2020). Molecular immune pathogenesis and diagnosis of COVID-19. Journal of Pharmaceutical Analysis.

243 Johns Hopkins University and Medicine (2020). https://coronavirus.jhu.edu/map.html. (Accessed $244 \quad 16$ May 2020).

245 Mason-D’Croz, D., Bogard, J. R., Herrero, M., Robinson, S., Sulser, T. B., Wiebe, K., . \& Godfray, 246 H. C. J. (2020). Modelling the global economic consequences of a major African swine 247 fever outbreak in China. Nature Food, 1(4), 221-228. 
248 Nature (2020). Coronavirus research updates: Antiviral antibodies peter out within weeks after 249 infection doi: 10.1038/d41586-020-00502-w. (Accessed 18 July 2020).

250 251

252

253

254

255

256

257

258

259

260

261

262

263

264

265

266

267

268

Nicola, M., Alsafi, Z., Sohrabi, C., Kerwan, A., Al-Jabir, A., Iosifidis, C., ... \& Agha, R. (2020). The Socio-Economic Implications of the Coronavirus and COVID-19 Pandemic: A Review. International Journal of Surgery.

Russell, B., Moss, C., George, G., Santaolalla, A., Cope, A., Papa, S., \& Van Hemelrijck, M. (2020). Associations between immune-suppressive and stimulating drugs and novel COVID-19-a systematic review of current evidence. ecancermedicalscience, 14.

Shi, Y., Wang, Y., Shao, C., Huang, J., Gan, J., Huang, X., \& Melino, G. (2020). COVID-19 infection: the perspectives on immune responses.

Singh, R., \& Avikal, S. (2020). COVID-19: A decision-making approach for prioritization of preventive activities. International Journal of Healthcare Management, 1-6.

Srivastava, R. K., \& Wagh, S. (2020). Factors impacting consumer purchase behaviour for pharmaceutical products. International Journal of Healthcare Management, 13(2), 113-121.

Tufan, A., GÜLER, A. A., \& Matucci-Cerinic, M. (2020). COVID-19, immune system response, hyperinflammation and repurposing antirheumatic drugs. Turkish Journal of Medical Sciences, 50(SI-1), 620-632.

WHO (2020). Coronavirus disease (COVID-2019) situation reports. https://www.who.int/emergencies/diseases/novel-coronavirus-2019/situation-reports. (Accessed 16 May 2020).

World Pandemic Index (2020). https://worlduncertaintyindex.com/data/. (Accessed 19 July 2020). 


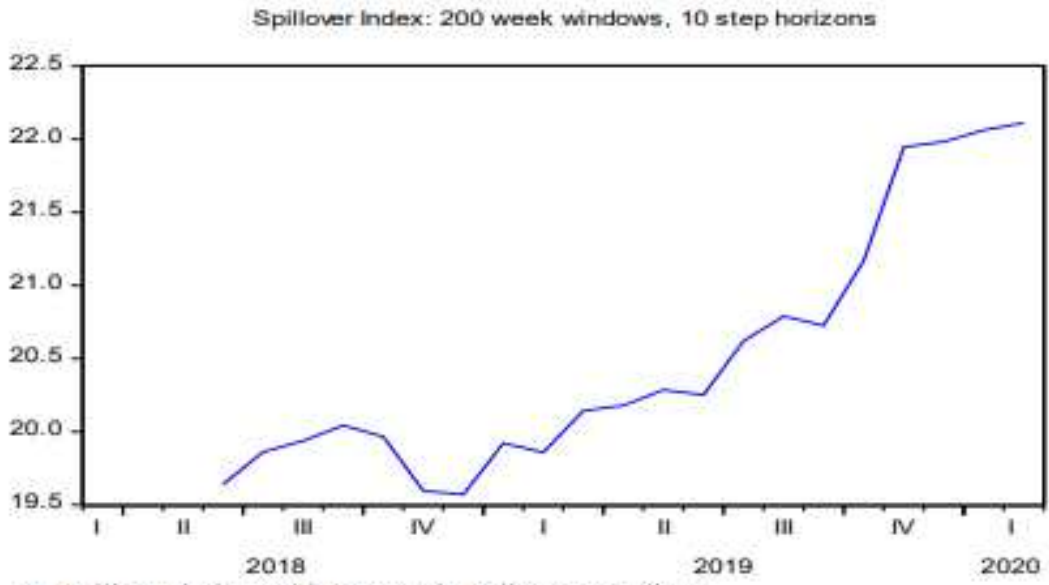

A: Rolling window with Economic Policy Uncertainty

Spillover Index: 200 week windows, 10 step horizons

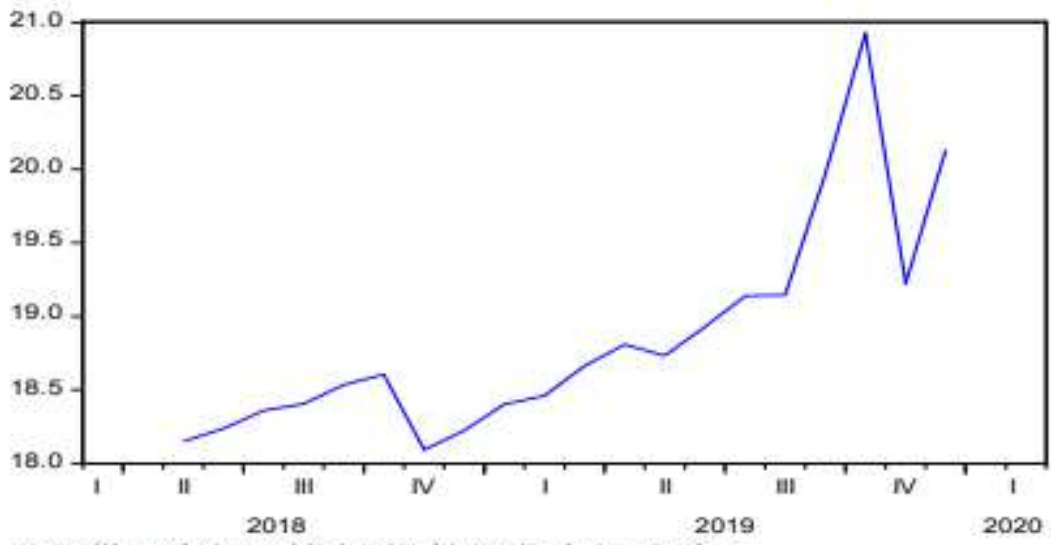

B: Rolling window with the World Pandemic Uncertainty

Spillover index: 200 week windows, 10 step horizons

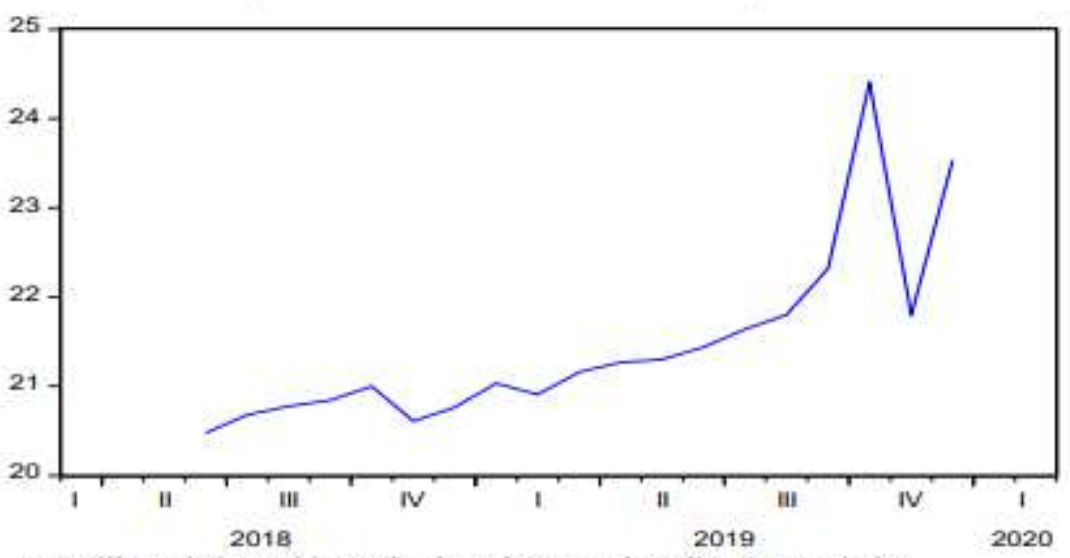

C: Rolling window with Pandemic and Economic Policy Uncertainties

\section{Figure 1}

A: Rolling window with Economic Policy Uncertainty. B: Rolling window with the World Pandemic Uncertainty. C: Rolling window with Pandemic and Economic Policy Uncertainties 